\title{
Bile Duct Injury Stories
}

\author{
Vinay K. Kapoor
}

\subsection{My Tryst with Destiny: Cholecystectomy and Bile Duct Injury}

\section{Manali Arora}

All readers are urged to go through the story of Manali Arora who had to undergo multiple operations and interventions for a bile duct injury sustained at a laparoscopic cholecystectomy performed in 2006.

Arora M, Kapoor VK. My tryst with destiny cholecystectomy and bile duct injury. National Medical Journal of India 2010; 23: 32-33.

The article is available at http://archive.nmji. in/archives/Volume-23/Issue-1/PDF-volume-23issue-1/Speaking-For-Myself.pdf

Manali had to undergo a right hepatectomy in 2008. After finishing her MBBS from Gauhati Medical College, Guwahati Assam in 2011, Manali obtained MD (Radio-Diagnosis) in 2015 from Assam Medical College, Dibrugarh Assam and then passed DNB (RadioDiagnosis) in 2017. Manali married Vishal Thakker in 2015. After working as Assistant Professor of Radiology at Pramukhswami Medical College, Anand Gujarat, she is currently pursuing a Post Doctoral Certificate Course (PDCC) in Breast Radiology at the All India Institute of Medical Sciences (AIIMS), Rishikesh Uttarakhand.

\subsection{Doctor, Is this My Last Surgery?}

Shweta Amrita Lakra

Lakra SA, Kapoor VK. Doctor, is this my last surgery? Indian Journal of Surgery 2018; 80: 377-381.

The article is available at https://link.springer. com/article/10.1007/s12262-017-1675-2

Shweta was operated for her bile duct injury in 2014. She obtained her PhD (Environmental Sciences) from the Indian Agricultural Research Institute (IARI), New Delhi in February 2017. Shweta married Pankaj Abhishek Toppo in January 2017. After working as Assistant Professor (Environmental Sciences) at St Xaviers College, Ranchi Jharkhand, she is currently a Food Safety Officer with Government of Jharkhand.
V. K. Kapoor $(\square)$

Department of Surgical Gastroenterology, Sanjay Gandhi Post-Graduate Institute of Medical Sciences (SGPGIMS), Lucknow, Uttar Pradesh, India 